\title{
Actinomicose em receptor de transplante renal: relato de caso e revisão da literatura
}

\section{Actinomycosis in renal transplant recipient: Case report and literature review}

Isabela Orieta de Oliveira Macedo ${ }^{1}$. Francisco Daniel Bezerra Amorim ${ }^{1}$. Evelyne Santana Girão ${ }^{1}$. Sonia Leite da Silva ${ }^{1,2}$. Paula Frassinetti Castelo Branco Camurça Fernandes ${ }^{1,3}$. Claudia Maria Costa de Oliveira ${ }^{1,4}$.

1 Hospital Universitário Walter Cantidio (HUWC), Fortaleza, Ceará, Brasil. 2 Universidade de Fortaleza (UNIFOR), Fortaleza, Ceará, Brasil. 3 Universidade Estadual do Ceará (UECE), Fortaleza, Ceará, Brasil. 4 Centro Universitário Christus, Fortaleza, Ceará, Brasil.

\section{RESUMO}

A actinomicose é uma doença rara, infecciosa, granulomatosa crônica, progressiva, e causada, na maioria dos casos, pela bactéria Gram-positiva e anaeróbia Actinomyces israelii. A doença pode assemelhar-se a outros processos infecciosos e até mesmo neoplásicos, dificultando seu diagnóstico e comprometendo o êxito terapêutico, e às vezes evoluindo para sérias complicações. Os autores relatam o caso de uma paciente de 54 anos, transplantada renal há 4 anos, apresentando uma lesão em região hipotenar na mão direita. Foi realizada investigação com exames de imagem e biópsia, tendo como diagnóstico actinomicose cutânea primária. O objetivo desse trabalho é discutir sobre uma patologia rara e de localização incomum, em uma paciente imunossuprimida, ressaltando a importância do diagnóstico precoce e preciso para o sucesso terapêutico.

Palavras-chave: Actinomicose. Transplante renal. Mãos.

\section{ABSTRACT}

Actinomycosis is a rare, infectious, chronic, progressive, granulomatous disease caused in most cases by Gram-positive and anaerobic bacterium Actinomyces israelii. It may resemble other infectious and even neoplastic processes, making it difficult to diagnose and compromise therapeutic success, and may lead to serious complications. The authors report the case of a 54-year-old female, who had undergone renal transplantation 4 years ago, presenting a hypothenar region in her right hand. He undertook investigation with imaging and biopsy tests, with the diagnosis of primary cutaneous actinomycosis. The objective of this study is to discuss a rare pathology and of unusual location in an immunosuppressed patient, emphasizing the importance of early and accurate diagnosis for therapeutic success.

Keywords: Actinomycosis. Kidney transplantation. Hands.

Autor correspondente: Isabela Orieta de Oliveira Macedo, Rua dos Manguezais, número 60, Dionísio Torres, Fortaleza, Ceará. CEP: $60135-640$. Telefone: +55 88 99615-7217. E-mail: isabelaorieta@hotmail.com

Conflito de interesses: Não há qualquer conflito de interesses por parte de qualquer um dos autores.

Recebido em: 20 Jun 2019; Revisado em: 09 Ago 2020; Aceito em: 26 Out 2020. 


\section{INTRODUÇÃO}

A actinomicose é uma doença bacteriana granulomatosa supurativa crônica, rara e progressiva. Foi descrita há mais de um século, sendo causada pelo microrganismo do gênero Actinomyces, representado pela bactéria Gram-positiva e anaeróbia Actinomyces israelii, sendo esta a forma mais prevalente isolada em infecções humanas, porém, já se têm descrito outras espécies. ${ }^{1}$

A bactéria coloniza normalmente a boca, os tratos digestivo e genital de humanos, tendo como apresentação clínica típica a actinomicose cervicofacial, seguindo infecção de foco dentário, a actinomicose pélvica em mulheres com dispositivo intrauterino e a actinomicose pulmonar em fumantes com pobre higiene dental, podendo também mimetizar processos malignos em vários sítios anatômicos, sendo outras localizações incomuns., ${ }^{2,3}$ Caracteriza-se pela presença de uma massa endurecida, com parede fibrosa e área de abscesso central, com secreção purulenta, que se difunde através dos tecidos moles, muitas vezes drenando através de fístulas. ${ }^{4}$

A manifestação clínica da lesão cutânea na actinomicose é semelhante a infecções cutâneas comuns, o que torna difícil o diagnóstico, sendo necessário uma forte suspeita clínica, principalmente em pacientes com exposição de feridas à saliva. ${ }^{5}$

Os autores relatam um caso de actinomicose cutânea primária em receptor de transplante renal, com uma localização incomum, uma vez que os locais mais comumente envolvidos são cabeça, pescoço, tórax e abdômen, e apresentando evolução favorável após tratamento clínico associado à abordagem cirúrgica.

\section{RELATO DO CASO}

Paciente, 54 anos, sexo feminino, tem como doença renal primária a síndrome do anticorcorpo antifosfolipídico. Foi submetida a um retransplante renal com doador falecido em 2013, com terapia imunossupressora de indução com timoglobulina e manutenção com tacrolimus, micofenolato e prednisona. Evoluiu bem, com boa função renal (creatinina $0,9 \mathrm{mg} / \mathrm{dl}$ ) e apresentava como comorbidades hipertensão arterial sistêmica e diabetes mellitus pós-transplante. Um primeiro transplante renal com doador falecido havia sido realizado em 2012, com perda imediata por trombose arterial, apesar de anticoagulação profilática.

Em abril de 2017, apresentou uma lesão em região hipotenar da mão direita, indolor, inicialmente eritematosa, evoluindo com nodulações, áreas hemáticas e pustulosas (Figura 1), sem sintomas constitucionais, mas com relato de dor e sangramento de pequena intensidade ao realizar limpeza local. Fez investigação com biópsia da lesão tendo sido diagnosticada actinomicose cutânea primária (Figura 2). Foi realizada ressonância magnética de mão direita para avaliar comprometimento ósseo, sendo detectado aumento volumétrico de partes moles na região volar e medial do punho e mão direita, com extensão ao plano muscular da região hipotenar, compatível com a processo inflamatório/infeccioso, retináculo flexor não caracterizado, sugerindo erosão. Tenossinovite do flexor do $5^{\circ}$ raio, pequena quantidade de líquido na articulação piramidal-pisiforme, podendo traduzir sinovite ou processo inflamatório/infeccioso foram encontrados.

Figura 1. Lesão em região hipotenar da mão direita.

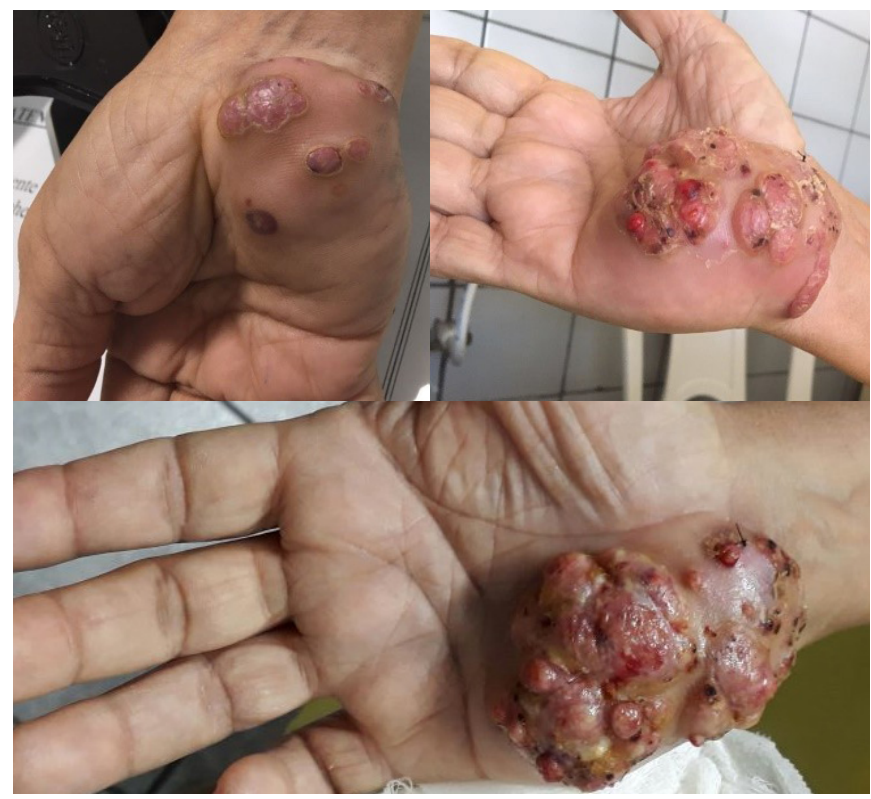

Figura 2. Camada córnea exibindo paraceratose e epiderme acantótica com leve espongiose. Derme edemaciada, com moderado infiltrado inflamatório misto, composto por linfócitos, plasmócitos e polimorfonucleares, além de numerosas células gigantes multinucleadas. Presença de grãos de Actinomyces sp.

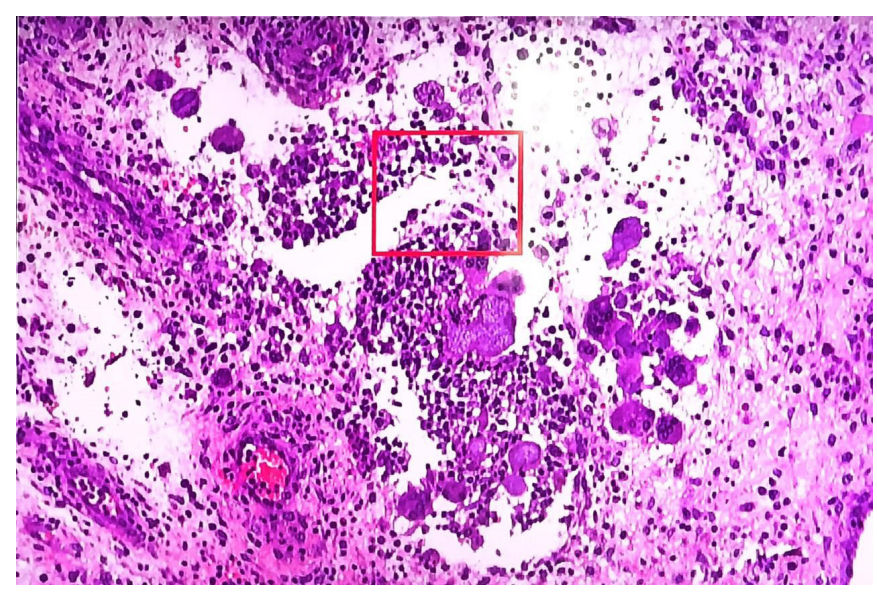

Realizada excisão cirúrgica (Figura 3) combinada ao tratamento antimicrobiano, inicialmente penicilina cristalina por 21 dias, ampicilina-sulbactam endovenoso por mais 7 dias e manutenção com amoxililina/clavulanato por 12 meses. No $3^{\circ}$ mês, as lesões regrediram completamente (Figura 4), mas evoluiu com suspeita de nefrite intersticial por amoxicilina, sendo convertida para clindamicina oral, com boa resposta. 
Figura 3. Lesão em região hipotensar após excisão cirúrgica.

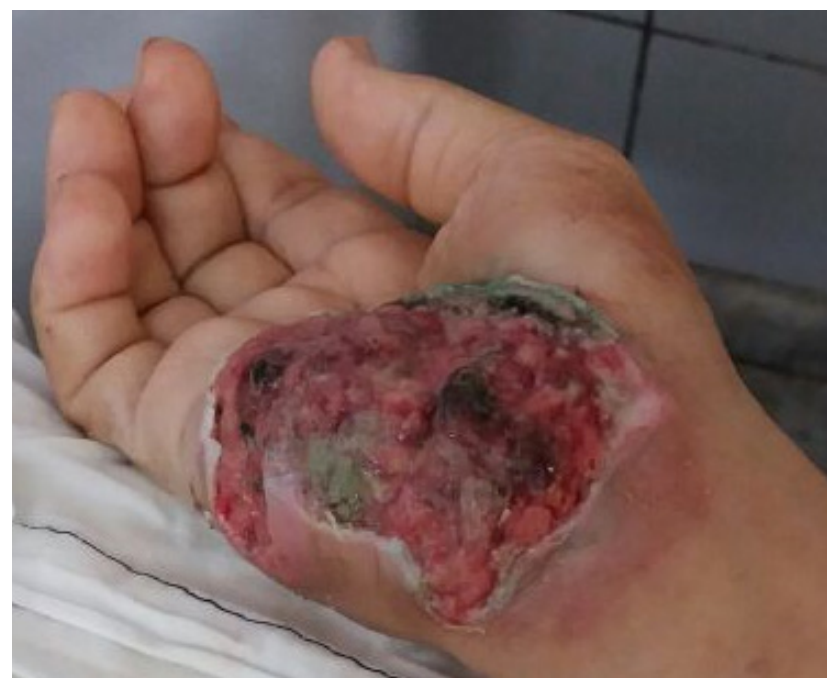

Figura 4. Regressão da lesão hipotenar na mão direita após o tratamento clínico-cirurgico.

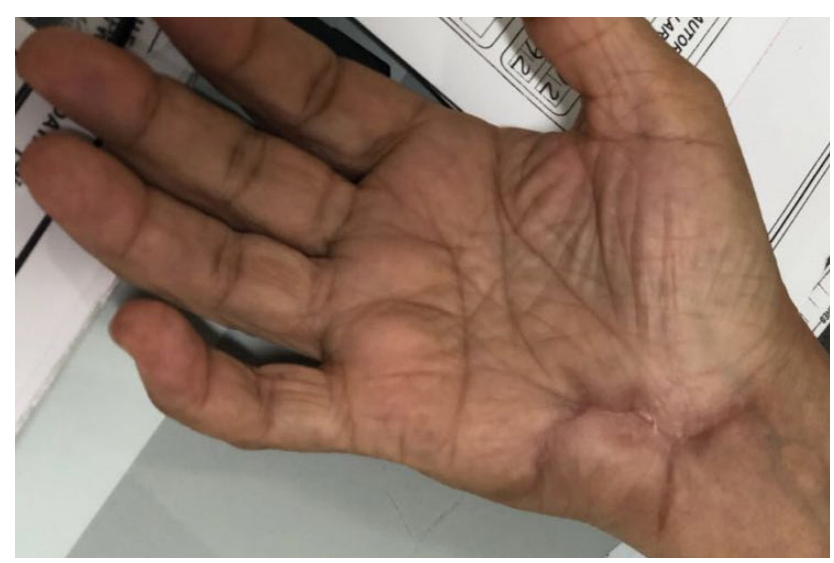

\section{DISCUSSÃO}

A actinomicose é mais frequente no homem, com uma proporção de 4:1. As lesões traumáticas são um importante mecanismo para infecção, podendo haver disseminação hematogênica para fígado, rins e articulações. $\mathrm{O}$ acometimento ósseo ocorre por contiguidade, podendo ser secundária à mordida humana. ${ }^{1}$

O Actinomyces desenvolve-se como uma infecção progressiva, causada por ferimentos teciduais, como trauma ou cirurgia. Este patógeno é menos virulento que as bactérias comuns,

\section{REFERÊNCIAS}

1. Vieira RL, Meirelles GS, Turrini E, Yamashita J, Oliveira HC, Fernandes AR. Actinomicose cutânea primária do pé simulando neoplasia de partes moles: relato de caso. Radio Bras. 2003;36(4):251-53.

2. Ferreira HP, Araújo CA, Cavalcanti JF, Miranda RL, Ramalho RA. necessitando de uma pele não íntegra e um meio anaeróbico para causar doença. Diabetes, imunossupressão e neoplasias malignas estão associados ao desenvolvimento da doença. ${ }^{5,6}$ No presente caso a paciente apresentava duas destas condições de risco. Entretanto, a paciente não recordava de qualquer trauma prévio na região da mão direita, porém, referindo contato prévio com jardinagem que pode ter ocasionado um trauma como porta de entrada.

Exames de imagem são importantes na avaliação da infecção musculoesquelética. A ultrassonografia pode ser utilizada para avaliar a presença e aspiração de coleção. A ressonância magnética e a tomografia computadorizada são importantes para avaliar a extensão da lesão, sendo o uso do contraste na ressonância importante para diagnóstico da infecção em partes moles ou ósseas. ${ }^{7}$

A identificação do Actinomyces a partir de um material estéril confirma o diagnóstico de actinomicose. A biopsia cirúrgica do tecido é o método mais apropriado. A identificação dessas bactérias ocorre na minoria dos casos, sendo a suspeita de actinomicose muito importante para garantir que a cultura apropriada seja realizada. No presente caso, o diagnóstico foi possível pela visualização na biópsia de grãos de Actinomyces spp, não havendo positividade nas culturas. Resultados falsos negativos na cultura são ocasionados por uso de antibiótico prévio, inibição do crescimento por microrganismos concomitantes ou contaminantes, condições inadequadas de cultura ou incubação inadequada em curto prazo. ${ }^{8}$ A microscopia evidencia necrose com grânulos de enxofre amarelado, constituídos por aglomerados de bactérias Gram-positivas filamentosas. ${ }^{9}$

O tratamento consiste no uso de antibióticos e desbridamento cirúrgico da lesão. ${ }^{6}$ Geralmente, o Actinomyces spp é sensível ao uso de beta-lactâmicos, sendo as drogas de escolha no tratamento. A associação com inibidores da beta-lactmase não é útil, pois os Actinomyces não produzem beta-lactamase. A utilização de clindamicina e macrolídeos tem mostrado eficácia como alternativa ao tratamento..$^{10,11}$

\section{CONCLUSÃO}

Os autores relataram um caso incomum de actinomicose de extremidade em uma paciente transplantada renal com boa evolução após tratamento cirúrgico e antibacteriano. $\mathrm{O}$ diagnóstico através de biopsia da lesão foi fundamental, sendo sua suspeição importante para que se possa fazer diagnóstico diferencial com neoplasias e outras infecções e o tratamento correto.
Pulmonary actinomycosis as a pseudotumor: a rare presentation. $\mathrm{J}$ Bras Pneumol. 2011;37(5):689-93.

3. Yang CH. Primary cutaneous actinomycosis of an extremity: a caserReport. J Intern Med Taiwan. 2010;21:290-3. 
4. Carneiro GG, Barros AC, Fracassi LD, Sarmento VA, Farias JG. Actinomicose cervicofacial: relato de caso clínico. Rev Cir Traumatol Buco-Maxilo-Fac Camaragibe. 2010;10(1):21-6.

5. Wasyłyszyn T, Borowska K. Cutaneous actinomycosis. A case report. Our Dermatol Online. 2016;7(4):451-2.

6. Alamillos-Granados FJ, Dean-Ferrer A, García-López A, LópezRubio F. Actinomycotic ulcer of the oral mucosa: an unusual presentation of oral actinomycosis. Br J Oral Maxillofac Surg. 2000;38(2):121-3.

7. Resnick D, Niwayama G. Osteomyelitis septic arthritis and soft tissue infection organisms. In: Resnick D, editor. Diagnosis of bone and joint disorders. 3. ed. Philadelphia: WB Saunders; 1995. p. 2448-558.
8. Valour F, Sénéchal A, Dupieux C, Karsenty J, Lustig S, Breton P, et al. Actinomycosis: etiology, clinical features, diagnosis, treatment, and management. Infect Drug Resist. 2014;7:183-197.

9. Heffner JE. Pleuropulmonary manifestations of actinomycosis and noardiosis. Semin Respir Infect. 1988;3:352-61.

10. Wong VK, Turmezei TD, Weston VC. Actinomycosis. BMJ. 2011;343:d6099.

11. Mandell GL, Bennett JE, Dolin R, editors. Mandell, Douglas, and Bennett's principles and practice of infectious diseases. 7. ed. Philadelphia: Churchill Livingstone Elsevier; 2010.

\section{Como citar:}

Macedo IO, Amorim FD, Girão ES, Silva SL, Fernandes PF, Oliveira CM. Actinomicose em receptor de transplante renal: relato de caso e revisão da literatura. Rev Med UFC. 2021;61(1):1-4. 